EDITORIAL

\title{
In This Issue: Back to Basics: Talking, Listening, and Low-Tech Primary Care
}

\author{
Jobn J. Frey III, MD, Associate Editor \\ Ann Fam Med 2011;9:98-100. doi:10.1370/afm.1233.
}

\section{TALKING WITH AND LISTENING TO PATIENTS}

Communication plays a central role in 3 manuscripts in this issue: communication with patients about health risk, communications with family and patients about end-of life-care, and communication with patients with intellectual disabilities. As one of my teachers once reminded me, we may send a signal to someone, but the message they receive depends on the person. Describing cardiovascular risk in a dispassionate and accurate way is a goal for counseling patients about risk, but Goodyear-Smith and colleagues showed that patients prefer to know what their doctor thinks and prefer visual depictions to words; those who prefer words respond to relative risk language better than absolute risk. ${ }^{1}$ Knowing the patient, once again, is crucial to choosing the most useful method of counseling and encouraging behavior change.

Women with and without intellectual disabilities may receive the same information about reasons for and risks of mammography, but as Wilkinson and colleagues show, those with intellectual disabilities have very different understandings and get different messages. ${ }^{2}$ The authors show that standard communication really needs to be individualized. As many practices have increasing numbers of patients with such disabilities, clinicians need training and better information about how to work with them to address fears and concerns. When we talk about cultural competence, we also need to include understanding and working with the cultures associated with disabilities.

Do patients increase their risk of a major clinical depression because of developing a chronic illness, or does a preexisting tendency toward depression manifest itself once a chronic illness is encountered? The answer from Naranjo and colleagues is yes! ${ }^{3}$ Spending time, as they outline, understanding a patient's history of depression and looking at the patient's affective response to developing diabetes both increase the likelihood of identifying patients with diabetes whose depression might challenge their ability to adhere to therapeutic guidelines.

Using large national data sets, Do and colleagues describe how well physicians are talking with patients about self-care relating to approaches outlined in the guidelines for managing osteoarthritis. ${ }^{4}$ They found an increase in counseling about weight loss but no changes in counseling about exercise and arthritis care. Unfortunately, advice is just that and says nothing about whether the advice is followed. Increasing use of guidelines to improve patient function begs the need for a new model of delivery of primary care that takes the burden off physicians and places it on teams of care with both expertise and time to work with patients.

Two studies look at measuring patient-centered care, a central value in modern medicine: a systematic review of the instruments currently in use to measure the degree of patient-centeredness in clinical work, and the development of a scale for determining physician trust of patients. ${ }^{5,6}$ On one hand, does the patient feel that the clinicians are attending to the patient's concerns, worries, and needs, and how do we know that? On the other, do clinicians trust what patients are telling them, and how would we measure that? In a review of instruments for patient-centeredness by Hudon and colleagues, ${ }^{5}$ the authors categorize existing measures, finding that all instruments share some core elements. But beneath it all, the feeling of connectedness to a physician is often driven by whether that clinician attends to patients thoughtfully and sensitively over time. The instrument measuring trust of patients ${ }^{6}$ was developed in an environment that is not easily generalizable-a clinic serving patients infected with the human immunodeficiency virus who have a high use of chronic pain medications. A concern for many educators is that students and residents may be quick to mistrust patients because of issues of social and cultural ignorance on the part of the learner. Whether we trust patients who seem more like us and, 
conversely, mistrust those who are not is an important issue to address early and often. Effective patient care is based on mutual trust. Requiring that patients prove that they are trustworthy while not requiring the same of clinicians is the wrong way to develop a relationship.

In their editorial, Epstein and Street $^{7}$ elaborate on important components of patient-centered care, as well as offer educational and organizational ideas to improve the process. "Training physicians to be more informative, mindful, and empathic" as they put it, is training that should be as rigorous and ongoing as any cognitive or procedural education for family doctors. Despite the wide availability of clinical information for both patients and clinicians, the success of any medical system still rests on the doctor-patient relationship. As McWhinney put it in 1975, "to restore the primacy of the person, one needs a medicine that puts the person in all his wholeness in the center of the stage and does not separate the disease from the man, and the man from his environment." 8

\section{FINDING OUT WHAT WORKS, AND LOW-TECH PRIMARY CARE}

This issue of the Annals contains several studies that test whether doing something makes a difference either in diagnosis or outcome. The first is a study of whether a trial of oral corticosteroids makes a difference in diagnosing chronic obstructive lung disease (COPD) in a cohort of patients. ${ }^{9}$ Although the results do not recommend substantial changes in the management of patients who suffer from the condition, the study does help clinicians be better informed and should help frame conversations with patients with COPD. In the end, the authors hand the decisions about clinical management back to clinicians and their patients.

A colleague of mine used to talk about creating a center for primary care technology, which he envisioned as low tech, low cost, and high yield. Two studies in this issue of the Annals might qualify as studies from such a center. Coppin, Wicke, and Little, in a delightful office-based study, look at the common problem of recurring earwax and show clearly that, by instructing patients with earwax buildup in selfcare using drops and bulb syringes, there is a $50 \%$ decrease in subsequent visits for earwax removal by those patients. ${ }^{10}$ While not a high-cost problem compared with such chronic diseases as diabetes, visits for wax removal take time and money and have an effect on access to limited primary care appointments. In my own department, we calculated that of 450,000 yearly patient visits to the University of Wisconsin family medicine clinics, 1,800 visits for earwax removal accounted for more than $\$ 250,000$ in charges. Time and money might be better spent in other preventive programs that have more serious consequences. In addition, following this method allows us to act on the precepts of patient-centered care by giving patients more control over this bothersome condition.

van der Wel and colleagues ${ }^{11}$ use the lowest technology possible — sitting quietly_to show that sitting for 30 minutes in a quiet room with serial blood pressures is as useful in diagnosing reactive or white-coat hypertension as is standard 24-hour continuous ambulatory blood pressure monitoring. The challenge in many clinical facilities may be finding a quiet room for 30 minutes, but this study may save many patients not only from being labeled as hypertensive but also the traditional costs and trouble of finding that out. And sitting quietly_or meditating — is a standard component of treatment as well.

Finally, Rosser and colleagues describe a successful experiment in Ontario Canada, with the provincial health system that developed organizational and economic incentives for groups of family doctors to create care teams to work with practice-based populations. ${ }^{12}$ The quick adoption of this structure by family doctors reinforces the basic tenets of population care and quality: a solid financial base with which to innovate, teams that are specific for specific populations, and a working environment that is driven by patient outcomes, not billing data. The process is early in its adoption, but preliminary reports - and the rapid change by most family doctors in Ontario to adopt this model_-seem to support wholesale rather than incremental reform.

Join the discussion of articles at http://www. AnnFamMed.org.

\section{References}

1. Goodyear-Smith F, Kenealy T, Wells S, Arroll B, Horsburgh M. Patients' preferences for ways to communicate benefits of cardiovascular medication. Ann Fam Med. 2011;9(2):121-127.

2. Wilkinson JE, Deis CE, Bowen DJ, Bokhour BG. 'It's easier said than done': perspectives on mammography for women with intellectual disabilities. Ann Fam Med. 2011;9(2):142-147.

3. Naranjo DM, Fisher L, Areán PA, Hessler D, Mullan J. Patients with type 2 diabetes at risk for major depressive disorder over time. Ann Fam Med. 2011;9(2):115-120.

4. Do BT, Hootman JM, Helmick CG, Brady TJ. Monitoring Healthy People 2010 arthritis management objectives: education and physician counseling for weight loss and exercise. Ann Fam Med. 2011;9(2):136-141.

5. Hudon C, Fortin M, Haggerty JL, Lambert M, Poitras M-E. Measuring patients' perceptions of patient-centered care: a systematic review of tools for family medicine. Ann Fam Med. 2011;9(2):155-164.

6. Thom DH, Wong ST, Guzman D, et al. Physician trust in the patient: development and validation of a new measure. Ann Fam Med. 2011;9(2):148-154. 
7. Epstein RM, Street RL Jr. The values and value of patient-centered care. Ann Fam Med. 2011;9(2):100-103.

8. McWhinney IR. Family medicine in perspective. N Engl J Med. 1975; 293:176-181

9. Broekhuizen BDL, Sachs APE, Moons KGM, et al. Diagnostic value of oral prednisolone test for chronic obstructive pulmonary disorders. Ann Fam Med. 2011;9(2):104-109.
11. Van der Wel MC, Buunk IE, van Weel C, Thien TABM, Bakx JC. A novel approach in office blood pressure measurement: 30-minute office blood pressure vs daytime ambulatory blood pressure. Ann Fam Med. 2011;9(2):128-135.

12. Rosser WW, Colwill JM, Kasperski J, Wilson L. Progress of Ontario's Family Health Team model: a patient-centered medical home. Ann Fam Med. 2011;9(2):165-171.

10. Coppin R, Wicke D, Little P. Randomized trial of bulb syringes for earwax-impact on health service utilization. Ann Fam Med. 2011;9(2):110-114.

\title{
EDITORIAL
}

\section{The Values and Value of Patient-Centered Care}

\author{
Ronald M. Epstein, $M D^{1,2}$ \\ Richard L. Street, $J r_{r}, P b D^{3,4}$ \\ 'Departments of Family Medicine, Psychiatry, Oncology, and Nursing, University of Rochester Medical Center, Rochester, New York \\ ${ }^{2}$ Center for Communication and Disparities Research, University of Rochester Medical Center, Rochester, New York \\ ${ }^{3}$ Department of Communication, Texas A\&M University, College Station, Texas \\ ${ }^{4}$ Houston Center for Quality of Care and Utilization Studies, Baylor College of Medicine, Houston, Texas
}

Ann Fam Med 2011;9:100-103. doi:10.1370/afm.1239.

$\mathrm{P}$ atient-centered care has now made it to center stage in discussions of quality. Enshrined by the Institute of Medicine's "quality chasm" report as 1 of 6 key elements of high-quality care, ${ }^{1}$ health care institutions, health planners, congressional representatives, and hospital public relations departments now include the phrase in their lexicons. Insurance payments are increasingly linked to the provision of patient-centered care. Lost in many of the discussions of patient-centered care, however, is the essential and revolutionary meaning of what it means to be patient

Conflicts of interest: authors report none.

\section{CORRESPONDING AUTHOR}

Ronald M. Epstein, MD

Center for Communication and

Disparities Research

University of Rochester Medical Center

1381 South Ave

Rochester, NY 14620

Ronald_Epstein@urmc.rochester.edu centered. The originators of client-centered and patient-centered health care were well aware of the moral implications of their work, which was based on deep respect for patients as unique living beings, and the obligation to care for them on their terms. Thus, patients are known as persons in context of their own social worlds, listened to, informed, respected, and involved in their care-and their wishes are honored (but not mindlessly enacted) during their health care journey. ${ }^{2-6}$ There have been concerns that patientcentered care, with its focus on individual needs, might be at odds with an evidence-based approach, which tends to focus on populations. Fortunately, that debate has been laid to rest ${ }_{i}$ proponents of evidence-based medicine now accept that a good outcome must be defined in terms of what is meaningful and valuable to the individual patient. ${ }^{7}$ Patient-centered care, as does evidence-based medicine, considers both the art of generalizations and the science of particulars. ${ }^{8}$

Patient-centered care is a quality of personal, professional, and organizational relationships. Thus, efforts to promote patient-centered care should 